\title{
CORRIGENDUM
}

\section{Boundary layer flow and bed shear stress under a solitary wave - CORRIGENDUM}

\author{
P. L.-F. Liu, Y. S. Park and E. A. Cowen \\ doi:10.1017/S0022112006004253, Published by Cambridge University Press, \\ 15 February 2007
}

Key words: corrigendum

This corrigendum notice is to inform the readers that we have discovered that some terms were missing in the nonlinear boundary-layer equation studied in the article by Liu, Park \& Cowen (2007), which gave a theoretical and experimental treatise of the bottom boundary layer under a solitary wave. The revision is available in a separate note (Park, Verschaeve, Pedersen \& Liu 2014), which shows some improvements in agreement between the revised theory and experimental data. Additional experimental data (Park 2009) were used for comparisons in the revision.

\section{REFERENCES}

LiU, P. L.-F., PARK, Y. S. \& Cowen, E. A. 2007 Boundary layer flow and bed shear stress under a solitary wave. J. Fluid Mech. 574, 449-463.

PARK, Y. S. 2009 Seabed dynamics and Breaking Waves, PhD thesis, Cornell University, Ithaca, New York.

Park, Y. S., Verschaeve, J., Pedersen, G. K. \& LiU, P. L.-F. 2014 Boundary layer flow and bed shear stress under a solitary wave: revision. J. Fluid Mech. 753, 554-559. 